\title{
CLIMA ORGANIZACIONAL E SUA INFLUÊNCIA NO ALCANCE DOS RESULTADOS DAS ORGANIZAÇÕES
}

Carina Garcia Lozano, Letícia Milani, Valdecir Cahoni Rodrigues, Alvaro Costa Jardim Neto

Universidade do Oeste Paulista - UNOESTE, Curso de Administração, Presidente Prudente, SP.

\section{RESUMO}

Apesar do tema não ser novo, e as questões sobre o mesmo ser estudadas a cada dia, mais do que a remuneração, hoje os colaboradores de uma organização procuram qualidade de vida, benefícios e desenvolver as suas atividades em um ambiente saudável, com o mínimo de conflitos pessoais possíveis, e acima de tudo um clima organizacional favorável. A pesquisa proposta teve como objetivo principal demonstrar que a oferta e manutenção de um bom clima organizacional entre outros fatores imprescindíveis que o torna palpável, e consequentemente empresas e colaboradores levarão a organização a alcançar melhores resultados, e principalmente os objetivos esperados. A pesquisa se focou em responder ao seguinte problema: como desenvolver e manter um bom clima organizacional entre empresa e colaboradores? A metodologia proposta para alcançar o objetivo e responder ao problema apresentado foi por intermédio de pesquisa qualitativa de cunho bibliográfico, buscando o máximo de fundamentação teórica, levantada por diversos autores, escritores, estudiosos e afins, proporcionando veracidade, além de credibilidade a pesquisa proposta. Concluiu-se que quando as organizações mantêm um bom clima organizacional os resultados são alcançados com muitos mais facilidade por parte dos colaboradores.

Palavras chave: Clima Organizacional, Organizações, Colaboradores, Objetivos, Resultados.

\section{ORGANIZATIONAL CLIMATE AND ITS INFLUENCE NON-SCOPE OF RESULTS OF ORGANIZATIONS}

\begin{abstract}
Although the theme is not new, and the questions about it are studied every day, more than the remuneration, today the employees of an organization seek quality of life, benefits and develop their activities in a healthy environment with minimum of possible personal conflicts, and above all a favorable organizational climate. The main objective of the proposed research was to demonstrate that the provision and maintenance of a good organizational climate, among other essential factors that make it tangible, and consequently companies and employees, will lead the organization to achieve better results, especially the expected objectives. The research focused on answering the following problem: how to develop and maintain a good organizational climate between company and employees? The methodology proposed to reach the objective and to respond to the presented problem was through a qualitative bibliographical search, seeking the maximum of theoretical foundation, raised by several authors, writers, scholars and the like, providing veracity and credibility of the proposed research. It was concluded that when the organizations maintain a good organizational climate the results are reached with much more ease on the part of the collaborators.
\end{abstract}

Keywords: Organizational Climate, Organizations, Collaborators, Objectives, Results. 


\section{INTRODUÇÃO E OBJETIVO}

Para obter um aumento nos resultados as organizações têm procurado novas estratégias para motivar os seus colaboradores. As estratégias tornaram-se necessárias uma vez que a geração Y que estão entrando no mercado de trabalho, não procura somente a remuneração, mas outros benefícios tais como qualidade de vida, liberdade de expressão, reconhecimento, plano de carreira, etc. Com o intuito de aumentar à valorização do capital intelectual as organizações têm investido em seus colaboradores como forma de manterem um bom clima organizacional, fato este que tem se tornado peça fundamental, que manuseada estrategicamente, além de reduzir doenças ocupacionais, minando também custos com demissões, contratações e redução significativa dos absenteísmos é fundamental para o alcance de objetivos e metas. (ULRICH, 2000).

Segundo Fleury e Sampaio (2002, p.291), o clima organizacional está atrelado "à percepção que as pessoas têm da organização em que trabalham", ou seja, consiste no que é abstraído pelo individuo dentro do ambiente de trabalho. Ainda nos dizeres de Motta (2001) as mudanças de comportamento das organizações fizeram com que as mesmas se preocupassem gradativamente, com os indivíduos em sua essência, desejos, suas necessidades e satisfações, buscando alternativas para envolverem os funcionários com os objetivos empresariais.

Envolver o colaborador com a cultura e os objetivos da organização de forma a mantê-lo motivado não é uma tarefa nada fácil para os gestores. Para Maximiano (2000, p. 339), uma das soluções é ter uma boa "comunicação como base para a liderança", já que não é possível persuadir, inspirar e motivar liderados, sem que haja uma capacidade eficaz em transmitir a mensagem que deseja.

Por intermédio de uma pesquisa bibliográfica, esta pesquisa buscou responder a seguinte problemática: Como desenvolver e manter um bom clima organizacional entre empresa e colaboradores? Quanto à hipótese acredita-se que o clima organizacional tem uma forte influência e pode interferir de maneira positiva ou negativamente no comportamento dos colaboradores das organizações. Desta maneira para a manutenção de um bom clima organizacional é necessário que o colaborador seja valorizado, recompensado, tenha liberdade de expressão, liberdade para tomar decisões, qualidade de vida, benefícios, e mais do que tudo isso, reconhecer esses fatos. Justifica-se esta pesquisa uma vez que os resultados obtidos poderão servir de conhecimento para que gestores de empresas reconheçam a importância de se investirem para que haja um bom clima organizacional, levando a empresa a tornar-se mais competitiva.

Assim, essa pesquisa teve como objetivo principal demonstrar como a oferta e manutenção de um bom clima organizacional entre empresas e colaboradores levarão a organização a alcançar melhores resultados.

\section{METODOLOGIA}

O alcance do objetivo geral e a resposta ao problema da pesquisa foram alcançados por intermédio da pesquisa qualitativa que segundo Minayo (1995, p. 21), nos explica que "a pesquisa qualitativa responde a questões muito particulares. Ela se preocupa, nas ciências sociais, com um nível de realidade que não pode ser quantificado".

A pesquisa também se caracteriza como exploratória pois, segundo Gil (2008), visa alcançar estudos de forma aproximativa sobre determinado fato, fornecendo uma visão ampla sobre o assunto. Além disso, a pesquisa utiliza do caráter bibliográfico cujo seu uso serviu para fundamentar o conceito de motivação, marketing e marketing multinível, e dentre os materiais bibliográficos deu-se ênfase em autores consagrados, na área, como Kiyosaki (2012), Worre (2014), entre outros. 


\section{RESULTADOS}

Para Maximiano (2000), clima organizacional é o nome dado para o produto dos sentimentos. Os sentimentos e as percepções que estão ligadas a realidade objetiva da organização são: satisfação, insatisfação e indiferença, sendo que esses sentimentos e percepções são influenciados por todos os componentes, desde o local físico até os objetivos. Tudo implica na maneira como as pessoas se sentem em relação à empresa.

Segundo Chiavenato (1999, p.440) clima organizacional pode ser conceituado como: "um conjunto de propriedades mensuráveis do ambiente de trabalho, percebidas direta ou indiretamente, pelos indivíduos que vivem e trabalham neste ambiente e que influencia a motivação e o comportamento de pessoas.".

É por meio da pesquisa que é possível medir o grau de relacionamento entre o colaborador e a organização. Para Payne; Mansfield (1973), o clima organizacional consiste em uma ligação conceitual entre o nível individual e o nível organizacional, no âmbito de expressar a compatibilidade ou adequação das expectativas, valores e interesses individuais com as necessidades, valores e condutas formais. Já para Rizzatti (2002), devem-se considerar algumas de suas características, através de estudos de aspectos conceituais, da análise e da identificação de categorias com seus componentes e indicadores relacionados que contribuam com a construção de modelos específicos para sua análise em determinadas organizações. Segundo Chiavenato:

Ele representa o conjunto de sentimentos predominantes numa determinada empresa e, envolve a satisfação dos profissionais tanto com os aspectos mais técnicos de suas carreiras e trabalho quanto aspectos afetivos/emocionais, refletindo em suas relações com os colegas de trabalho, com os superiores e com os clientes de modo geral. É a tendência de percepção que os membros de uma organização possuem a respeito de seu grau de satisfação em relação ao conjunto ou a determinada característica desta organização (CHIAVENATO, 1999, p. 126).

O autor deixa claro que o grau de satisfação e comprometimento dos colaboradores com a organização, bem como a relação com os demais funcionários, é reflexo do clima organizacional.

Segundo Martins (2008, p. 29), a percepção dos empregados sobre o ambiente de trabalho tem se tornado fator imprescindível para as organizações, face às rápidas transformações que estão surgindo nos anos de globalização, as organizações buscam cada vez mais conhecer melhor a dinâmica da vida organizacional, objetivando identificar como trabalhadores expostos a uma série de estímulos procedentes da organização e do ambiente de trabalho têm compreensões similares, dando significados semelhantes às características importantes da vida organizacional.

Uma das formas para melhor compreender a definição de clima organizacional é considerar algumas de suas propriedades, seja por meio do estudo de aspectos conceituais, ou da análise e da identificação de categorias com seus componentes e respectivos indicadores que possam contribuir com a elaboração de modelos específicos para sua análise em determinadas organizações. (RIZZATTI, 2002).SOUZA (1978), conclui que, o clima é uma consequência da cultura organizacional, há uma relação entre os dois, e considera que cultura e clima têm efeito sobre os resultados das empresas, podendo ser positivo ou negativo.

Chiavenato concorda que não existe melhor ou pior indivíduo e que o comportamento é função do seu ambiente, e sugere ao gestor a construção de um clima organizacional "realizador", a fim de estimular tal comportamento em pessoas com pouca motivação para isso.

Chiavenato (1999 p.267), explica que quando constatada elevada motivação entre os integrantes, o clima organizacional cresce positivamente, refletindo em relações de satisfação, de animação, interesse e colaboração. Porém, quando é ao contrário, ou há barreiras na satisfação das necessidades, o clima organizacional tende a regredir, caracterizando-se por estado de depressão, desinteresse, apatia e insatisfação. 
O Clima Organizacional tem sido então, considerado fator de grande relevância para a gestão organizacional, principalmente após as mudanças consequentes do processo de globalização e internacionalização das organizações (KELLER; AGUIAR, 2004). Luz (2001 p.14), administrar o clima organizacional se tornou uma estratégia para todas as organizações, em particular, às que se julgam empenhada sem relação a gestão da qualidade, pois não é possível obter qualidade nos produtos ou serviços se não houver qualidade na vida pessoal e profissional de quem os executam.

Luz (2001, XIX), afirma que só é possível entender e melhorar as relações entre as pessoas nos diversos âmbitos de trabalho, a partir de pesquisa de clima organizacional e acrescenta que "[...] amplia-se a importância sobre informações indispensáveis para o adequado gerenciamento dos recursos humanos, e por sua influência decisiva na produtividade" A pesquisa de clima organizacional é uma ferramenta de planejamento estratégico, que além de outros benefícios, proporciona uma análise interna e externa da organização e acompanhando o estado de satisfação e comprometimento dos empregados com a empresa (SILVA, 2003).

O principal foco da pesquisa de clima organizacional para as organizações é melhorar e maximizar as suas relações com os seus colaboradores oferecendo-lhes condições de trabalho adequadas, proporcionando-lhes oportunidades de desenvolvimento pessoal e profissional e estabelecendo um satisfatório ambiente de trabalho, levando em consideração que, "se o clima for desfavorável, a reação dos indivíduos e grupos será opositora à obtenção de resultados positivos". Mello (2004, p. 17). Rizzati (2002) concorda que pesquisar e analisar o clima organizacional estão longe de ser uma tarefa fácil, já para Nepomuceno (2004, p. 12), considera o clima organizacional um fenômeno fácil de ser percebido, mas difícil de ser compreendido, já que o mesmo envolve vários fatores de ordem pessoal e de ordem organizacional. A maior fatia da gestão e das políticas de gestão organizacional está relacionada ao desenvolvimento, recompensas e avaliação dos trabalhadores e, separadamente, à gestão de questões tais como saúde, bem-estar, segurança e relações de trabalho.

Ferraz; Holanda (2007) apontam que análise de clima organizacional relacionada ao desempenho financeiro das empresas deveria ser algo natural, como qualquer outra atividade corriqueira da empresa, a fim de ser possível acompanhamento das metas empresárias e compará-las com o desempenho dos indivíduos das organizações.

\section{DISCUSSÃO}

Analisando as referências bibliográficas obteve-se respostas concretas sobre o tema abordado referente às influências inegáveis que o clima organizacional reflete nos resultados e objetivos organizacionais. É nítido que uma organização deve além de administrar seus recursos financeiros, administrar também seus recursos humanos pois é de onde obtém os seus resultados esperados.

Resultados de produtividade nas organizações são consequências de um conjunto de fatores de condução de aspectos relacionados à gestão de pessoas, bem como do clima organizacional, conhecimento da cultura organizacional e de colaboradores em suas particularidades, já por parte dos gestores, além de habilidades e o mínimo de domínio no quesito motivação e qualidade de vida.

Esta pesquisa respondeu por intermédio de uma pesquisa bibliográfica a seguinte problemática: Como desenvolver e manter um bom clima organizacional entre empresa e colaboradores? A resposta está em o gestor compreender a área onde atua, quem são seus componentes, e não ignorar as fortes influências. 


\section{CONCLUSÃO}

A cada dia mais e mais as organizações desenvolvem estratégias para retenção de seu capital intelectual. Reter os profissionais significa tornar-se competitivas perante suas concorrentes. Uma das formas de reter tem sido investir para manter um bom clima organizacional e para isso há a necessidade de investir em programas de remuneração, qualidade de vida, motivação e outros fatores.

É nítido que quando se investe no funcionário haverá a manutenção de um bom clima organizacional e consecutivamente haverá uma influencia no alcance dos resultados/metas/objetivos da mesma.

Para a manutenção de um bom clima organizacional é necessário a organização investir em qualidade de vida, programas de motivação, remuneração estratégica, programas de benefícios, etc. Estas e outras políticas devem ser implementadas e mantidas para que o funcionário se sinta satisfeito.

Desta maneira conclui-se que um bom clima organizacional terá impacto positivo junto aos funcionários na obtenção dos resultados da organização.

\section{REFERÊNCIAS}

CHIAVENATO, I. Gerenciando Pessoas. 3. ed. São Paulo: Makron books, 1999.

FERRAZ, S. F. S.; SILVA HOLANDA, M. Alinhamento entre indicadores de resultados organizacionais e de pessoas: proposição de um modelo diagnóstico. In: ENCONTRO NACIONAL DA ASSOCIAÇÃO NACIONAL DE PROGRAMAS DE PÓS-GRADUAÇÃO EM ADMINISTRAÇÃO, 31., 2007, Rio de Janeiro. Anais. Rio de Janeiro: Anpad, 2007. 1 CD-ROM.

FLEURY, M. T. L; Sampaio, J. D. R. Uma discussão sobre cultura organizacional. em: Fleury, M. T. L. (org.) As pessoas na organização. 2. ed. São Paulo: Gente, 2002.

KELLER, Edevais; AGUIAR, Maria Aparecida Ferreira. Análise crítica teórica da evolução do conceito de clima organizacional. Terra e Cultura. Londrina, v. 20, n. 39, p. 91-113, 2004

KIYOSAKI, Robert. O Negócio do século XXI. 1. ed. Rio de Janeiro: Elsevier, 2012.

LUZ, J. P. Metodologia para análise de clima organizacional: um estudo de caso para o Banco do Estado de Santa Catarina. 2001. 213f. Dissertação (Mestrado em Engenharia de Produção) Universidade Federal de Santa Catarina, Florianópolis, 2001.

MARTINS, M.C.F. 2008. Clima organizacional. In: M.M.M. SIQUEIRA (org.), Medidas do comportamento organizacional: ferramentas de diagnóstico e gestão. Porto Alegre, Artmed.

MAXIMIANO, A.C.A. Teoria Geral da Administração: da escola científica à competitividade na economia globalizada. 2. ed. São Paulo: Atlas, 2000

MELLO, M. S. de O. A qualidade do clima organizacional como variável interveniente no desempenho humano no trabalho. Um estudo de caso da empresa Herbarium. Florianópolis, 2004. (Dissertação de Mestrado)

MINAYO, Maria Cecilia de Souza (org.). Pesquisa Social: Teoria, Método e Criatividade. Petrópolis: Vozes, 1995. 
MOTTA, P. R. Transformação organizacional: a teoria e a prática de inovar. Rio de Janeiro: Qualitymark, 2001.

NEPOMUCENO, A. C. Diagnóstico do clima organizacional como instrumento de gestão empresarial: o caso da Companhia Siderúrgica Belgo Mineira. 2004. 81f. Dissertação (Mestrado em Engenharia de Produção) - Universidade Federal de Santa Catarina, Florianópolis, 2004.

PAYNE, R. L.; MANSFIELD, R. Relationship of perceptions of organizational climate to organizational structure, context e hierarchical position. Administrative Science Quarterly, n. 18, p. 515-526, 1973. https://doi.org/10.2307/2392203

RIZZATTI, G. Categorias de análise de clima organizacional em universidades federais brasileiras. 2002. 305f. Tese (Doutorado em Engenharia de Produção) - Universidade Federal de Santa Catarina, Florianópolis, 2002.

SILVA, N. T. da. Clima organizacional: uma proposta dos fatores a serem utilizados para avaliação do clima de uma instituição de ensino superior. 2003. 138f. Dissertação (Mestrado em Engenharia de Produção) - Universidade Federal de Santa Catarina, Florianópolis, 2003

SOUZA, E. L.P de. Clima e Cultura Organizacional: Como se manejam. São Paulo: E.Blucher, 1978.

ULRICH, D. A. The test of Gross Motor Development. 2. ed. Austin, Texas: Prod-Ed., 2000.

WORRE, Eric. Go Pro: 7 passos para se tornar um profissional do Marketing de Rede 1. ed. Rio de Janeiro: Propósito Eterno, 2014. 